\title{
Aus dem Vorwort der früheren Jahrgänge.
}

Das "Auskunftsbuch für die chemische Industrie“ soll, wie sein Name besagt, dem Chemiker und Industriellen der einschlägigen Gebiete in den Fragen der Praxis Auskunft erteilen; es ist nicht zum Unterricht bestimmt und nimmt eine Mittelstellung zwischen Lehrbüchern und lexikalischen Werken ein. Die rein alphabetische Anordnung gewährt eine schnelle Übersicht; die kurze, prägnante Darstellung, die alles weniger Wichtige und Theoretische übergeht, vermeidet einen übermässigen Umfang, der die Handlichkeit stören müsste.

Seinem Zwecke entsprechend, berücksichtigt das Buch, nach grossen Schlagwortgruppen geordnet, alle für die chemische Industrie sowie für den praktischen Gebrauch im chemischen Laboratorium wichtigeren Stoffe und Produkte, weiter die Materialien zu ihrer Erzeugung, dann die Fabrikationsmaschinen und Apparate, 'Untersuchungsinstrumente, Gerätschaften u. s. w.

Bei den einzelnen Artikeln sind, soweit tunlich, die Formeln, Atom- bzw. Molekulargewichte, die wichtigen und üblichen Darstellungsmethoden mit den Reaktionsgleichungen, spez. Gewichte, Schmelzund Siedepunkte, Lösungskoeffizienten, thermo- und elektro-chemische Daten, tabellarische Übersichten u.s. w. verzeichnet - alles nach Möglichkeit dem derzeitigen Stande der Technik angepasst.

Mit lebhaftem Danke müssen wir der weitgehenden Unterstützung gedenken, die uns von seiten der chemischen Industrie und der damit in Berührung stehenden Firmen mit wenigen Ausnahmen überall entgegengebracht worden ist, und die es uns allein ermöglicht hat, der chemischen Technik mit wirklich zuverlässigen Angaben zu dienen.

Selbstverständlich kann das Buch nicht dem Spezialtechniker Winke für die Fabrikation seine $r$ Artikel geben; das verbietet der Umfang und ist auch nicht der $Z$ weck des Buches. Dagegen soll das Auskunftsbuch die chemische Technik so we it zusammenfassen, dass es dem Nachschlagenden ermöglicht, sich über alle ihm selbst ferner stehenden Spezialgebiete in willkommener Weise zu informieren und das zu rekapitulieren, was sonst dem Chemiker bei der Mannig- 
faltigkeit der Einzelzweige gar nicht alles gegenwärtig bleiben kann.

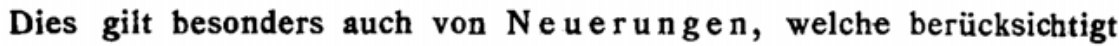
wurden, soweit sie sich praktisch bewährt haben und soweit sich zuverlässige Angaben darüber erlangen liessen. Die gegebenen tabellarischen Übersichten, Zahlenangaben usw. werden selbstverständlich auch dem Spezialtechniker nützlich erscheinen.

Wir betonen immer wieder, dass nur die Unterstützung aller Kreise der chemischen Industrie unser Werk zu dem machen kann, was es werden will: zu einem willkommenen Jahrbuch, zu einem zuverlässigen Ratgeber, zu einem vertrauenswürdigen Nachschlagebuch für die Praxis.

Allmählich ist das „Auskunftsbuch“ ein notwendiges Ausrüstungsstück der Fabriken und Laboratorien, der Chemiker, Apotheker, Industriellen u. s. w. geworden, und mit Freude und Genugtuung dürfen wir darauf hinweisen, dass das In- wie das Ausland, Kritiker der Zeitschriften wie andere hervorragende Fachleute einig sind in dem Lobe über das Gebotene und über die von Auflage zu Auflage gesteigerte Menge an Neuerungen, Erweiterungen und Verbesserungen. -

Bei der Bearbeitung einer jeden Auflage ist ein sehr reiches Material zu berücksichtigen, das von Jahr zu Jahr noch immer zu wachsen scheint. Hierdurch veranlasst, und in besonderer Berücksichtigung der Interessen des ganzen Leserkreises hat die Redaktion eine Tendenz immer mehr in den Vordergrund gerückt - die Tendenz nämlich, das aufzunehmende Neue soweit wie möglich kritis ch zu s i c h t e n. Allerdings bleibt man in dieser Hinsicht - besonders bezüglich der Pate nt liter a t u r - von Irrtümern und Missgriffen nicht frei. So wird manches Verfahren mit erwähnt, das aussichtsreich scheint und sich doch in der Praxis unbrauchbar erweist, während es umgekehrt vorkommt, dass patentierte Verfahren, die man nach anderen Erfahrungen als unbrauchbar weglassen möchte, doch ïberraschend gute Erfolge geben. Das sind Missstände, die sich nicht vermeiden lassen und die wir den Leser zu entschuldigen bitten; überall wurde unter Zugrundelegung von Auskünften und unter Berücksichtigung des Rates von Spezialfachleuten das richtige Mass zu halten gesucht. Jedenfalls wird der Leser - in einem dem Rahmen des Ganzen entsprechenden Umfange - fast alles von beachtenswerten Neuerungen erwähnt finden. 
Auf die immer erneuten Wünsche zahlreicher Praktiker hin wurde eine umfangreiche Tabelle über die Bedeutung der im Auskunftsbuch der Raumersparnis wegen zahlreich verwendeten Formeln aufgenommen, die den genannten Interessenten besonders willkommen sein wird, die aber als Gedächtnisbehelf wohl auch sämtlichen andern Lesern gute Dienste leisten kann.

Was die unter den einzelnen Artikeln verzeichneten Bezugs. quellen und die eingefügten Inserate anlangt, so sei ausdrücklich betont, dass die Einschiebungen von einem Auftrage der betreffenden Firmen beim Verlage abhängen und mit dem Text der Artikel nichts zu tun haben; die Redaktion hat hinsichtlich des Textes überall strengste Objektivität gewahrt. Ein Adressbuch ist das vorliegende Werk nicht; deshalb wäre es unangebracht, unter den Firmen alle Lieferanten zu suchen oder überhaupt die Angabe von Firmen als einen integrierenden Bestandteil des Werkes zu betrachten. Aber wir hoffen, dass die Bereitwilligkeit des Verlages, Bezugsquellen mit aufzunehmen, unseren Lesern in vielen Fällen eine wertvolle. und willkommene Information hinsichtlich der Lieferanten gewähren wird. 
